\title{
A Management Engineering Look at Cataloging
}

Mr. Kingery is chief, Preparations Division, New York Public Library.

\section{Scope and Method}

$\mathrm{F}$ Rom February I to June I5, I95I, the firm of Cresap, McCormick and Paget, management engineers, of New York and Chicago, made a survey of the preparation procedures of the Reference Department of The New York Public Library. On August I5, I95 I, the survey staff presented a written report of their findings to the director of the library including seventy-five recommendations for changes in preparation procedures.

In general, the methods used in this survey were the same as those employed by Cresap, McCormick and Paget in their previous survey of the Acquisition Division of The New York Public Library Reference Department. ${ }^{1}$ However, the survey of preparation procedures had three different principal objectives: (I) more expeditious handling so that new acquisitions would reach the shelves, and related cards would reach the official and public catalogs in a minimum of elapsed time, (2) lower processing costs to be achieved by a maximum rate of sustained output by all members of the staff who participated in preparation activities, and (3) the highest practicable level of accuracy and consistency to assure correct cataloging, and minimize misfiling of cards, misplacement of books, and similar errors. These objectives

1 Cf. Morris, T. D., "Techniques of Appraising the Administrative Strength of an Organization." College and Research Libraries, I3:III-II 6, April, I952. stressed adequacy of service to users of the Reference Department collections as well as economy in the performance of preparation tasks.

The scope of the survey included a study of ( $I$ ) organization, that is, the assignment of duties and authority throughout the Reference Department of The New York Public Library for search, processing, classification, subject heading, descriptive cataloging, indexing, catalog maintenance and preparation of materials for shelving; (2) staffing, that is, the numbers and qualifications of personnel required to perform each step expeditiously and accurately; (3) controls, that is, the statistics and reporting systems needed to provide current, continuing measures of the time and cost of work produced and the condition of the workload; (4) methods, that is, the flow of work, routines, forms and mechanical devices employed; and (5) physical factors, that is, the location, layout, furnishing and convenience of facilities provided.

While copies of the survey report are not for sale, a limited number of copies are available on inter-library loan upon application to the director of The New York Public Library.

\section{Findings}

The findings and recommendations of the survey represent an unusual degree of collaboration between the survey staff of Cresap, McCormick and Paget and the members of the Reference Department most directly concerned with preparation functions, and are, in large measure, the product 
of joint analysis and discussion. Therefore, it is not surprising that seventy of the recommendations have, with minor adjustments, been either fully implemented or are in process of being carried out. Because of the number of recommendations, it is not feasible to discuss each one in detail. Some of the recommendations have no application outside the Reference Department while others seem to be of wide interest and application. The following discusion is limited to the latter.

\section{Provision of Staff Assistants}

The Preparation Division carries on all cataloging, recataloging and preparation of materials for the Reference Department except manuscripts, prints, sheet maps, ephemera, material in non-Roman alphabets, and material for the Berg and Arents collections: During the fiscal year I950-5I, the division cataloged 66,880 titles. It is staffed with approximately 1 to full time positions. The salary budget is roughly a half million dollars. Because of the variety and extent of the functions of the Preparation Division, the survey recommended that the chief of the division be provided with four staff assistants, namely (I) a technical assistant to help in the screening, sorting, and routing of material prior to searching and cataloging; (2) a professional assistant to aid in developing division-wide cataloging rules and policies, and training plans and programs for catal cgers and candidates for cataloging positions; (3) an administrative assistant to compile and analyze workload and staffing reports and to conduct continuing work simplificaticn, work measurement and personnel utilization studies; and (4) an editor of the catalogs to revise and establish subject and classification systems, to develop plans for weeding and revising the catalogs, and to plan "consumer surveys" of the catalogs.
Separation of Cataloging and Preparation Actions

The survey staff distinguished the actions within the Preparation Division as of two kinds: ( I ) cataloging, and (2) preparation, and recommended that the division be organized into two functional branches responsible for these two major areas of activity. The effect of this recommendation is to reduce the direct span of control for the chief of the Preparation Division from eleven independent sections to two. The chief line assistant in the Cataloging Branch is the chief cataloger. He supervises five sections: ( I) Processing, (2) Jet Cataloging, ${ }^{2}$ (3) Advanced catalog planning, (4) Serial catalog planning, and (5) Entry investigaticn. The principal line assistant in the Preparation Branch is the head of preparation who supervises four sections: ( I) Adding and card correction, (2) Card preparation, (3) Materials handling, and (4) Filing. The effect of this recommendation is to simplify and clarify the organization and to provide stronger supervision and control.

\section{Catalog Planning}

Previous to the survey, the Preparation Division was organized around form of material and the cataloging sections were: ( I) Subject heading and classification, (2) Monograph descriptive, (3) Serial descriptive, (4) Document descriptive, and (5) Reserve, or rare book. The survey recommends that the Cataloging Branch be o:ganized around subjects rather than forms of material. This recommendation is based on the view that the cataloging job is a whole job of planning approaches between a piece of material and its potential users, that the job should not be broken up as it

2 The Jet Cataloging Section handles material which presents no anticipated difficulty as to choice of main entry, or of descriptive detail, and is staffed with college graduates and library school students. 
had been on the basis of subject analysis vs. description, and that the significant differences among materials, in terms of use, lie in differences in subject and not differences of form. The effect of this recommendation is to have catalogers gradually handle materials within a subject area regardless of form of material, and to do the whole job of catalog planning for that material, including subject analysis and description. For this purpose, the survey recommends the development of a catalog planning sheet which originates in the Process Section and travels with the piece of material until card copy is prepared for reproduction and the material is prepared for the shelves. This form takes the place of many forms previously in use.

\section{Entry Investigation}

Previous to the survey, entry investigation, including authority work, was done by the individual cataloger. The survey recommended that entry determination be separated from entry establishment. The effect of this recommendation is that catalog planners determine what the main, added, and subject entries are to be, while the preparation of authority cards and the determination of the final form of personal and corporate names are the responsibility of the Entry Investigation Section. In this connection, the Preparation Division applies the "no-conflict" principle in the establishment of personal names, tends to use corporate names as they appear on publications, and ordinarily catalogs serials under title as published.

\section{Aggregation and Extension of Process $W$ ork}

Initially, process work was dispersed among the various catalog sections. The survey recommended that all process work be brought together in a Process Section within the Cataloging Branch, and that process work be extended to include adding of serials (except when cataloging changes are involved), preliminary selection of entry and the provision of other cataloging information available from the official catalogs of the Reference Department such as entries for and classification of previous editions, form of series entry, form of established entries and whether or not a conflict exists.

\section{Adding and Card Correction}

Originally, adding and card correction was carried on in the various cataloging sections. The survey urged that all adding and card correction actions be separated from the proposed Cataloging Branch in order to concentrate this branch fully on the professional aspects of cataloging, and be carried on in an Adding and Card Correction Section within the Preparation Branch. The survey further recommended that all serial adding be done in the Process Section using tabulated cards to the end that serial catalogers be involved in the handling of incoming serial material only when a change in catalog planning on the face of catalog cards is involved.

In place of the former practice of removing cards from catalogs, charging them, correcting the cards, and then refiling in the various catalogs, and removing the charges, the survey suggested the correcting of the official catalog cards and their reproduction photographically to provide corrected cards for the other catalogs. These corrected cards are then simply substituted for the no-longer-correct cards already in the catalogs.

\section{Use of LC Cataloging Information}

The survey distinguished between the use of LC printed cards and the use of cataloging information available from sample LC cards or from proofsheets. Previously, the Reference Department of The New York Public Library made extensive use of LC printed cards. During the fiscal year 
1950-5I, 6 per cent of the new catalog cards were individually typed, 45 per cent were obtained from the Library of Congress, and 49 per cent were prepared by the New York Public Library in its own printing office using letterpress equipment. After careful and detailed study of the costs of card preparation, of "transferring" (i.e. of adapting LC cards, of modifying form of personal and corporate entries and subject tracings to correspond to forms already established in the catalogs, of adding classmarks to all cards), and the elapsed time between receipt of material and the availability of full sets of cards in the catalogs, the survey recommended that cards be reproduced by offset, using electric typewriters equipped with 8-point type for composition. This recommendation contemplated the full use in catalog planning of any cataloging information available from the Library of Congress in the form of sample cards or of proof, but discontinued the use of LC printed cards.

\section{Examination and Discussion}

Because of the close collaboration between the survey staff and the staff of the Preparation Division, the examination and discussion of the survey report moved smoothly. Full opportunity was given the staff to examine the survey and its plan of installation. The director of the library released the report to the chief of the Preparation Division on August I 5. Copies were then given to each supervisor of the division for study. On September 13, the director called a meeting of the supervisors of the Preparation Division to discuss the adequacy of the fact-finding of the survey staff, the reactions of the supervisory staff of the division to the general recommendations of the report, and the probable reactions of the staff of the division as a whole to the report. As a result of this discussion, and because of the enthusiastic approval of the supervisors, the director authorized the release of the report to the staff. Ranking assistants in each section were assigned the reading of the report as a whole during working hours, and other assistants were given time to read as much of the report as they wished. Through the middle of October, the chief of the division held a series of supervisory meetings on the report covering each of the 75 recommendations in detail and the plan of installation phase by phase. These meetings were attended by all section heads and their ranking assistants. Minutes of these meetings were taken and distributed to the director, the chief of the Reference Department, and to each section of the division. Within each section, the minutes were routed to all staff members. During the last week in October, the chief of the division met with the entire staff in eight appropriate groups to discuss the basic theory behind the various recommendations, to clarify misconceptions as to what the recommendations of the survey report actually were, and to answer specific questions. During this period, section heads were required to make a written report on their reactions to the survey and other staff members were invited to do so.

On November 7, the chief of the division presented to the chief of the Reference Department and the director of the library, a detailed report on the discussion and examination of the report by the staff of the Preparation Division. At that time, the staff urged the acceptance of sixty-two of the recommendations, the further examination of nine, and rejection of four. Since that time, additional study has led to the acceptance of seventy of the seventy-five recommendations.

Near the middle of November, the director again met with the supervisors of the Preparation Division, and at that time authorized the implementation of the recommendations acceptable to the supervisory 
staff of the division in accordance with the plan of installation included in the survey report. Since that time, a Committee on Reorganization, composed of the section heads of the division have met bi-weekly. The implementation of the report, like the survey itself, has been a close collaboration.

\section{Installation}

The survey staff included in their report, a detailed and specific "plan of installation" in a five-phase program: ( $\mathrm{I}$ ) organizing for installation, (2) planning for installation, (3) initial installation, (4) final installation, and (5) long-range actions. The time-span suggested was seventeen months for phases one to four. Just seven months after authorization to implement the survey, the Preparation Division is at the end of phase three and is just entering the "final installation."

\section{Results}

It is, of course, too early to tell what the final results of the survey and its recommendations will be. However, it is already clear that the first two of the three principal cbiects of the survey will be achieved. During the fiscal year $195 \mathrm{I}-52$, the division cataloged 90,736 titles as compared with 76,341 for the previous fiscal year. It is expected that we will handle I50,000 titles during the fiscal year just beginning, without any increase in staff. The elapsed time between the receipt of the material in the Division and the filing of all cards for that material in the catalogs has been substantially reduced so that one month is the average for material received in bound form.

Important as these results are, the "human" ones are undoubtedly more important and more enduring. Because of the close team work among the survey staff and the division staff, we now feel our problems can be solved, and that the day is not far distant when, without arrearages, we can enter phase five, "long-range action." These include studies of the use made of our catalogs, revision and weeding, study of the problems of subject analysis, the preparation of instructional material on the catalogs for the public, and part-time schedules for our catalog planners in the public divisions of the Reference Department.

Recently, the director asked one member of the division how she felt about the survey. Her answer was "Tired, but happy." That attitude seems characteristic of the staff of the whole division. Because of the close collaboration during the actual survey, the careful introduction of the report, and the participation of the staff in its implementation, the survey of the division will probably not be "over" for many years to come. What began as a management engineering look at cataloging has turned into a continuing, enthusiastic look at cataloging by a group of catalogers themselves.

\section{Drexel Library School Scholarships}

For the academic year 1953-54, the Drexel School of Library Science is granting three full tuition scholarships. These will be awarded to American citizens who are graduates of approved colleges or universities, and who are applying for entrance to the one-year curriculum leading to the degree of Master of Science in Library Science. Selection is based on academic standing, need for financial aid, and promise of high professional achievement.

Application for scholarship forms should be made to the Dean of the School of Library Science, Drexel Institute of Technology, 32nd and Chestnut Streets, Philadelphia 4, Pennsylvania, before April I, 1953. Inquiries concerning scholarship aid to foreign students should also be addressed to the Dean. 